\title{
The influence of extracellular buffer concentration and propionate on lactate efflux from frog muscle
}

M. J. Mason, G. W. Mainwood, and J. S. Thoden

Department of Physiology, University of Ottawa, 451 Smyth Road, Ottawa, Ontario K1H 8M5, Canada

Pflügers Arch (1986) 406:472 - 479

Equation (4) in this paper should be:

$Y_{\mathrm{e}}=Y_{\mathrm{o}}-\frac{J_{\mathrm{y}} \mathrm{X}^{\prime} l^{\prime}}{D_{\mathrm{y}} \alpha}+\frac{J_{\mathrm{y}} \mathrm{X}^{\prime 2}}{2 D_{\mathrm{y}} \alpha}$

where $\alpha=V_{\mathrm{e}} / \lambda$ 